\title{
ESTIMATING ROOT ZONE MOISTURE FROM SURFACE SOIL USING LIMITED DATA
}

\author{
OKREŚLANIE WILGOTNOŚCI GLEBY POWIERZCHNIOWEJ \\ W STREFIE KORZENIOWEJ \\ NA PODSTAWIE OGRANICZONEJ LICZBY DANYCH
}

\begin{abstract}
For estimation of root-zone moisture content from EO-1/Hyperion imagery, surface soil moisture was first predicted by hyperspectral reflectance data using partial least square regression $(P L S R)$ analysis. The textures of more than 300 soil samples extracted from a $900 \mathrm{~m} \times 900 \mathrm{~m}$ field site located within the Hetao Irrigation District in China were used to parameterize the HYDRUS-1D numerical model. The study area was spatially discretized into 18,000 compartments $(30 \mathrm{~m} \times 30 \mathrm{~m} \times 0.02 \mathrm{~m}$ ), and Monte Carlo simulations were applied to generate 2000 different soil-particle size distributions for each compartment. Soil hydraulic properties for each realization were determined by application of artificial neural network analysis and used to parameterize HYDRUS-1D to simulate averaged soil-moisture contents within the root zone $(0-40 \mathrm{~cm})$ and surface (approximately 0-4 cm). Then the link between surface moisture and root zone was established by use of linear regression analysis, resulting in $R$ and $R M S E$ of 0.38 and 0.03 , respectively. Kriging and co-kriging with observed surface moisture, and co-kriging with surface moisture obtained from Hyperion imagery were also used to estimate root-zone moisture. Results indicated that PLSR is a powerful tool for soil moisture estimation from hyperspectral data. Furthermore, co-kriging with observed surface moisture had the highest $R(0.41)$ and linear regression model, and HYDRUS Monte Carlo simulations had a lowest RMSE (0.03) among the four methods. In regions that have similar climatic and soil conditions to our study area, a linear regression model with HYDRUS Monte Carlo simulations is a practical method for root-zone moisture estimation before sowing and it can be easily coupled with remote sensing technology.
\end{abstract}

Keywords: Monte Carlo simulations, HYDRUS, root zone, soil moisture, kriging, co-kriging

\section{Introduction}

Irrigation is essential for crop cultivation in arid and semi-arid regions to increase the water availability in the soil and to leach a fraction of accumulated salts [1]. In the irrigated regions of northern China, a flood-irrigation system has been in development since the 1980s to reduce salinity levels in the root zone and increase water availability for spring

\footnotetext{
${ }^{1}$ State Key Laboratory of Water Resources and Hydropower Engineering Science, Wuhan University, Wuhan, 430072, P.R. China

${ }^{2}$ School of Remote Sensing and Information Engineering, Wuhan University, Wuhan 430079, P.R. China

${ }^{3}$ Changjiang Institute of Survey, Planning, Design and Research, Wuhan, 430010, P.R. China

*Corresponding author: huangjiesheng1962@gmail.com
} 
crops [2]. However, the flood-irrigation system may both cause a waste of water resources and present a risk of environment problems, such as groundwater pollution [3-5]. Therefore, it is important to supply the exact amount of irrigation water to crops that is required. This allocation of water is one of the most appropriate ways to reduce agricultural water use in water-scarce areas [6]. To determine the appropriate irrigation amount before sowing, precipitation, evaporation, crop species, and, especially, the initial soil-moisture information of the root zone should be taken in consideration [7].

The most common method of obtaining soil-moisture information is soil sampling and oven drying [8]. However, these in situ soil-moisture observations are both time-consuming and lacking over large spatial scales [9, 10]. The development of hyperspectral remote sensing provides a novel and effective way to obtain the topsoil properties. Hyperspectral sensors are different from conventional broadband sensors, such as SPOT [11], Landsat MSS [12], and Landsat TM [13], which are unsuitable for mapping soil properties because soil elements have characteristic features that mostly occur in narrow-wavelength regions and their bandwidths of 100-200 $\mu \mathrm{m}$ cannot resolve diagnostic spectral features of terrestrial materials. Hyperspectral remote sensing is an advanced technique that usually provides ample spectral information to delineate material characteristics [14]. This capability enables the identification of targets on the basis of their established spectral absorption features [15]. Ben-Dor et al. [16] indicated that nearly all soil components, including moisture, could be explored by hyperspectral inversion. However, for hyperspectral remote sensing, limitations still exist, especially with extending surface moisture information to the root zone. Previous research showed that geostatistical methods such as co-kriging could overcome these limitation by considering more than one variable to improve the prediction accuracy [17, 18]. Sun et al. [19] compared different geostatistical analysis methods for precipitation interpolation and found co-kriging methods that utilize altitude as the supplementary data could obtain the minimum root mean square error $(R M S E)$. Yates et al. [20] used co-kriging methods to estimate the gravimetric moisture content by regarding bare-soil surface temperature and the percent sand content as two additional data. Ghadermazi et al. [21] predicted the spatial distribution of nitrate concentration in drinking water by using $\mathrm{pH}$ as the auxiliary co-kriging variable. Therefore, we can also use the surface-soil moisture as a secondary variable for co-kriging to estimate root-zone moisture.

In addition, mathematical simulations of hydrology processes were also used to estimate root-zone moisture from surface soil [22]. For example, Blonquist Jr et al. [23] created a non-site-specific and physically constrained root-zone model by combining the finite-element HYDRUS-1D model with meteorological observations and artificial neural network analysis. Manfreda et al. [24] developed a physical approach for the estimation of root-zone soil moisture from surface measurements by analysis of assimilated data. However, these methods all need a time series of observations, which might be inconvenient to obtain in some regions. And it is still a challenge to estimate root-zone moisture from surface-soil conditions with very limited observations for these methods.

Therefore, the purposes of this study were to (1) obtain the surface-soil moisture of the study area using a hyperspectral inversion model, and (2) evaluate the accuracy of different methods of estimating root-zone moisture from surface soil moisture from a limited number of experimental observations. 


\section{Materials and methods}

\section{Study site and data collection}

Soil sampling was conducted in a square field of 81 ha, located in Hetao Irrigation District $\left(40^{\circ} 19^{\prime}-41^{\circ} 18^{\prime} \mathrm{N}, 106^{\circ} 20^{\prime}-109^{\circ} 19^{\prime} \mathrm{E}\right)$ of Inner Mongolia, China (Fig. 1). The climate of the study area is temperate continental and monsoonal. The average annual precipitation is $139-222 \mathrm{~mm}$, with approximately $60 \%$ of the rain falling in July and August. The annual potential evaporation is approximately $2200-2400 \mathrm{~mm}$. A grid and stratified sampling scheme was used on April 6 and April 26 in 2013 to take soil samples. More precisely, on April 6, soil samples were taken at nine depths: 0-2, 2-5, 5-10, 10-15, 15-20, 20-25, 25-30, 30-35, and 35-40 cm (red triangle in Fig. 1). On April 26, 227 sampling points were arranged and 114 points among them had the soil profile samples at depths of $0-5,5-10,10-20,20-30$, and $30-40 \mathrm{~cm}$ (blue circle and red triangle in Fig. 1). Another 113 sampling points had soil samples at $0-5 \mathrm{~cm}$ only (green circle in Fig. 1).

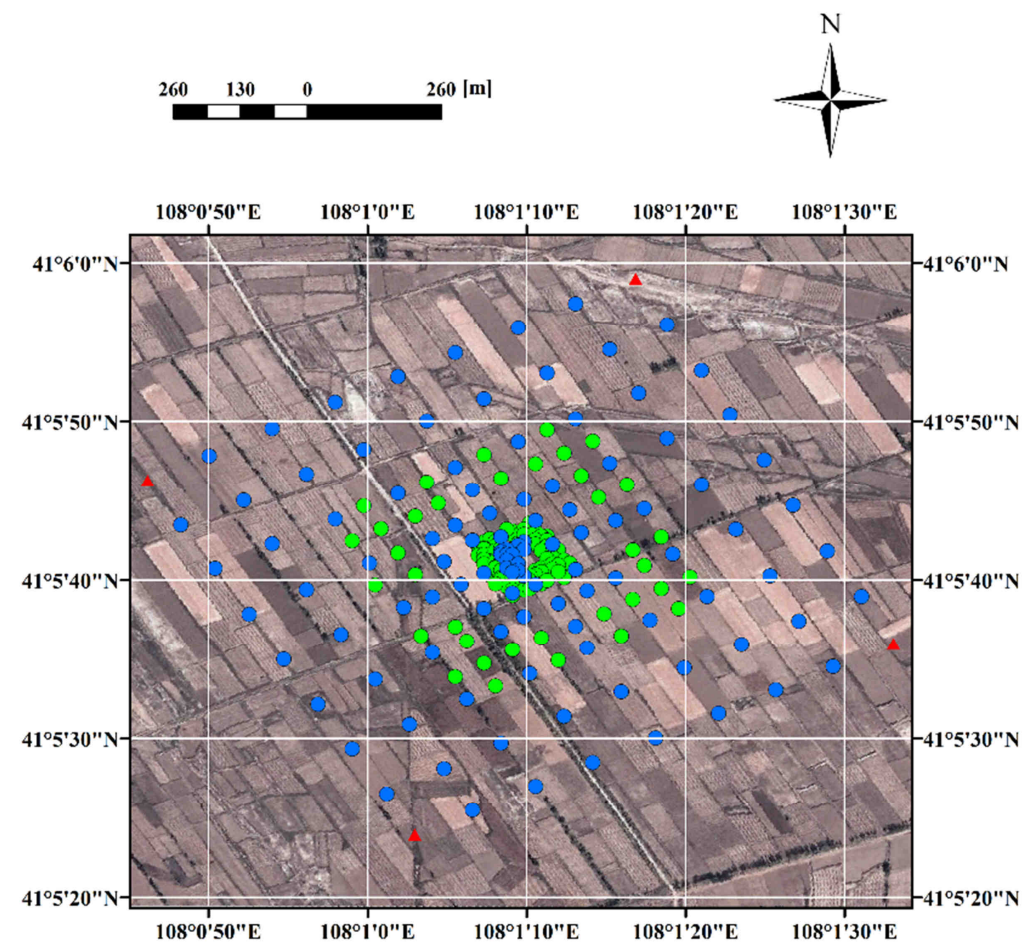

Fig. 1. Location $\left(40^{\circ} 19^{\prime}-41^{\circ} 18^{\prime} \mathrm{N}, 106^{\circ} 20^{\prime}-109^{\circ} 19^{\prime} \mathrm{E}\right)$ and overview (image from Google Earth) of the study site. Soil samples at red triangles were taken on April 6 and April 26 in 2013 as scheduled. Red triangle and blue circle points were taken for both surface and root zone. Green circle points were only taken for 0-5 cm depths

In addition, satellite and ground based hyperspectral data were collected during late April of 2013. The hyperspectral image before spring sowing was acquired by the EO-1/Hyperion sensor on April 11, 2013. The ground based soil reflectance data were 
acquired with an analytical spectral device (ASD, AgriSpec, Inc., 400-2500 nm, FOV, $25^{\circ}$ ) at the exact sampling locations where soil samples were collected on April 26. ASD soil reflectance data were taken from 10:00 am to 2:00 pm in the field, measured at nadir and 25 repeated readings were averaged as the ultimate hyperspectral data for each soil sampling point to minimize random noise. A white Spectralon panel by barium sulphate $\left(\mathrm{BaSO}_{4}\right)$ was used to get the absolute reflectance.

\section{Laboratory analysis}

Soil mass moisture content $\left[\mathrm{g} \cdot \mathrm{g}^{-1}\right]$ was measured for all soil samples by use of the oven drying method. Then we multiplied the mass of moisture content by $1.4 \mathrm{~g} \cdot \mathrm{cm}^{-3}$ (bulk density) to convert it into volumetric moisture content $\left[\mathrm{cm}^{3} \cdot \mathrm{cm}^{-3}\right]$. Electrical conductivity of 1:5 soil:water extraction $\left(E C_{1: 5}\right)$ of the $0-5 \mathrm{~cm}$ samples collected on April 26 were also measured by use of a conductivity meter (DDSJ-318, LEICI, China). In addition, we selected 42 0-5 cm samples collected on April 26 and all the soil samples collected on April 6 to perform particle-size analysis using the sieve-pipette method [25, 26].

\section{Pre-treatment of hyperspectral data}

The EO-1/Hyperion image was processed to Level $1 \mathrm{R}$ and then treated with Hyperion tools V2.0 integrated in ENVI/IDL software to eliminate empty bands, atmospheric water absorption bands, and overlapped bands from 242 original bands. Then, 155 bands with average full-width at half-maximum $(F W H M)$ of $10 \mathrm{~nm}$ were built up by visible near-infrared (VNIR) (426.8-925.4 nm) and short-wave infrared (SWIR) (933, 973-1366, 1477-1790, 1982-1992, and 2032-2355 nm). The vertical striping was nonexistent after band-by-band check, and the spectral smile was not significant after MNF (Minimum Noise Fraction Rotation) examination. Then, the Fast Line-of-Sight Atmospheric Analysis of Spectral Hypercube (FLAASH) in the ENVI software package was used for atmospheric correction, with standard options applied to converted the digital number $(D N)$ to apparent surface reflectance in accordance with the ASD data. In addition, seven ground control points were carefully selected to make geo-reference with $R M S E$ lower than 0.3 pixels.

The ASD data were used to establish near-surface soil-moisture prediction models. For the purpose of matching ASD data and EO-1/Hyperion image closer in spectral resolution and band position, the ASD data were resampled to $10 \mathrm{~nm}$ spectral resolution and the resampled ASD data were used as spectral reflectance in the following analysis.

\section{Surface soil moisture content estimation}

Experimental data of surface-soil moisture $(0-5 \mathrm{~cm})$ collected on April 26 were randomly divided into 2 subsets. One subset was used for model calibration and the other was used for model validation. Then, partial least square regression $(P L S R)$ and the variable importance in projection (VIP) were used to establish models for predicting surface moisture from hyperspectral data (ASD data). More precisely, PLSR is a kind of regression that was developed back in the 1980s [27-29]. It combines features from and generalizes principal component analysis (PCA) and multiple linear regression [30], which were beneficial for solving severe collinearity contained in hyperspectral reflectance [31]. Considering the facts that wavelength selection is necessary and important for the hyperspectral signature [32], we first used PLSR to establish a prediction model with first-order derivative filtered reflectance [33], and then we calculated the VIP. 
If a wavelength had a VIP that was higher than 1 and its regression coefficient ( $b$-coefficient) was higher than the standard deviation of all $b$-coefficients, it would be regarded as a significant wavelength and retained in our final model. Otherwise, it was removed. After, the VIP calculation, the new PLSR model was established with the remaining wavelengths and applied to estimate surface-soil moisture.

\section{Random field of soil hydraulic parameters}

Geostatistical analysis was first used to calculate the mean value, variance, and correlation scales in horizontal ( $X$ and $Y$ direction) and vertical ( $Z$ direction) sections of soil sand and clay percentages in our study area. Then, the study area was spatially discretized into 18,000 compartments $(30 \times 30 \times 0.02 \mathrm{~m})$, and Monte Carlo simulations were applied to generate 2000 different soil-particle size distributions for each compartment according to the geostatistical analysis results. After that, soil hydraulic properties of each compartment, including residual soil-water content $\left(\theta_{r},\left[\mathrm{~cm}^{3} \cdot \mathrm{cm}^{-3}\right]\right)$, saturated soil-water content $\left(\theta_{s}\right.$, $\left[\mathrm{cm}^{3} \cdot \mathrm{cm}^{-3}\right]$ ), empirical parameters $\alpha\left[\mathrm{cm}^{-1}\right]$, and $n$ in the van Genuchten-Mualem soil water retention function [34], and the saturated hydraulic conductivity $\left(K_{s},\left[\mathrm{~cm} \cdot \mathrm{d}^{-1}\right]\right)$ were predicted by artificial neural network $(A N N)$ analysis by use of Rosetta procedure [35].

\section{HYDRUS-1D simulation}

HYDRUS-1D (referred to hereafter as HYDRUS) was used in our study to simulate soil-water movement in each generated compartment with different soil hydraulic parameters. It uses a Galerkin-type linear finite element scheme to numerically solve the Richard's equation for saturated and unsaturated water flow. For more details about HYDRUS theory and applications, see He et al. [2].

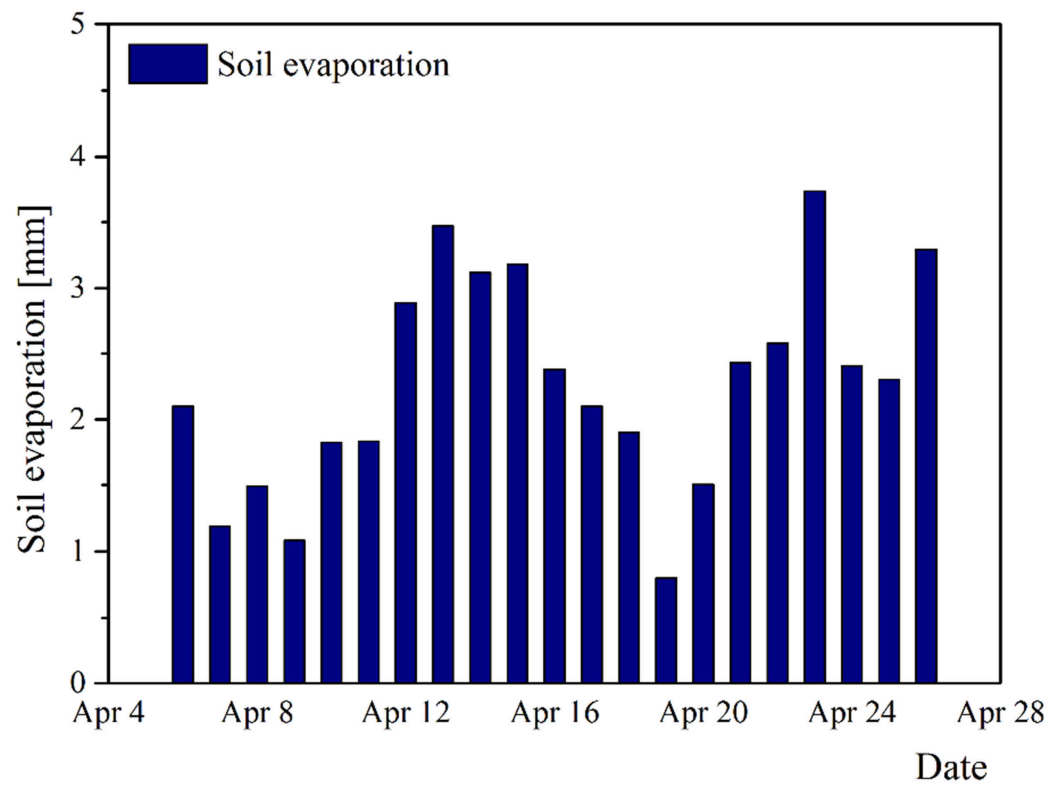

Fig. 2. Soil evaporation during the simulation period from April 4 to April 28 in 2013 . No precipitation occurred during this period 
In our study, the initial soil-water condition was obtained on the basis of laboratory analysis of soil samples taken on April 6, and the soil evaporation (Fig. 2) was calculated with HYDRUS according to the daily weather parameters provided by a weather station, which was located approximately $1500 \mathrm{~m}$ from our study area. The upper conditions of the soil profile correspond to atmosphere boundary conditions. Because we only wanted to determine the irrigation requirement before sowing, and the main crop of the study area was sunflower, with roots mainly in the $0-40 \mathrm{~cm}$ depth range while the groundwater depth was approximately at $200 \mathrm{~cm} \mathrm{[36],} \mathrm{the} \mathrm{lower} \mathrm{boundary} \mathrm{condition} \mathrm{was} \mathrm{free} \mathrm{drainage,} \mathrm{and} \mathrm{the}$ simulation period was from April 6 to April 26 in 2013. After simulation, the mean soil moisture from 0 to $4 \mathrm{~cm}$ depth and from 0 to $40 \mathrm{~cm}$ depth were both calculated, and we regarded the former as surface soil moisture $(S M)$ and the latter as the root-zone soil moisture $(R M)$.

\section{Estimation of root-zone moisture}

Four different methods for estimating root-zone moisture $(0-40 \mathrm{~cm})$ were evaluated in our study. More precisely, we used kriging with the measured root-zone moisture in the first method (M1). In the second method we applied the measured surface moisture as covariate and used co-kriging to obtain root-zone moisture (M2). In the third method (M3) the surface moisture estimated from hyperspectral imagery was used as the covariate in co-kriging. Finally, in the fourth method (M4) the relation between $S M$ and $R M$ from HYDRUS simulation was established using linear regression analysis:

$$
R M=a \cdot S M+b
$$

where $a$ and $b$ are regression coefficients.

\section{Model evaluation}

Pearson's correlation coefficient $(R)$ and $R M S E$ were used in our study to evaluate the model performance. The methods to calculate these statistical indexes are shown by:

$$
\begin{gathered}
R=\frac{\sum_{i=1}^{n}\left(Y_{i}^{\text {obs }}-Y_{i}^{\text {obsm }}\right)\left(Y_{i}^{\text {sim }}-Y_{i}^{\text {simm }}\right)}{\sqrt{\sum_{i=1}^{n}\left(Y_{i}^{\text {obs }}-Y_{i}^{\text {obsm }}\right)^{2}} \sqrt{\sum_{i=1}^{n}\left(Y_{i}^{\text {sim }}-Y_{i}^{\text {simm }}\right)^{2}}} \\
R M S E=\sqrt{\sum_{i=1}^{n} \frac{\left(Y_{i}^{\text {obs }}-Y_{i}^{\text {sim }}\right)^{2}}{n}}
\end{gathered}
$$

where $Y_{i}^{\text {obs }}$ and $Y_{i}^{\text {sim }}$ are the $i$ th observed and simulated value, respectively, and $Y_{i}^{\text {obsm }}$ and $Y_{i}^{\text {simm }}$ are averages of the $i$ th observed and simulated value, respectively.

\section{Results}

\section{Geostatistical analysis of soil-particle size}

The relation between semi-variance value and separation distance of the spatial distribution of sand and clay percentages are shown in Figure 3. A Gaussian model was used to fit the sand percentage in the horizontal ( $X$ and $Y$ direction) and vertical ( $Z$ direction) sections, and the $R^{2}$ values were both larger than $0.6(0.655$ and 0.651 , respectively), which indicated the fitting curve could reflect the semi-variance information accurately. For the distribution of clay percentage, a spherical model was used for fitting 
the horizontal section, whereas the vertical section was fitted by a Gaussian model. Furthermore, the fitting accuracy of clay percentage was also acceptable because the $R^{2}$ values were 0.601 and 0.486 for horizontal and vertical sections, respectively.

a)

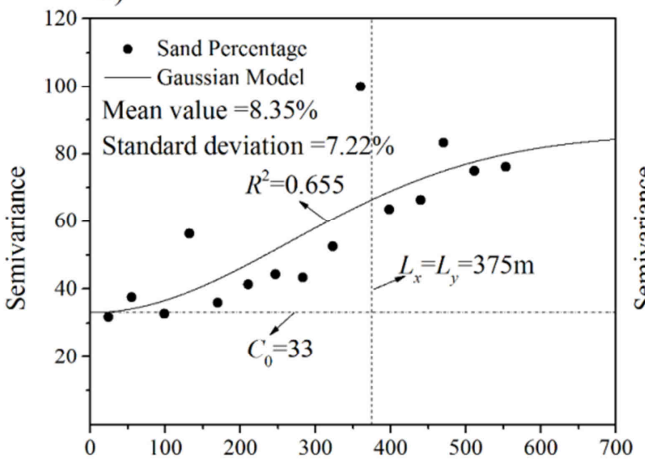

b)

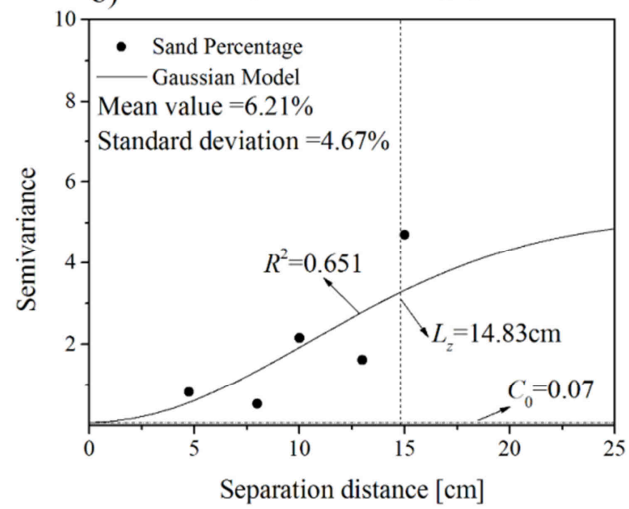

c)

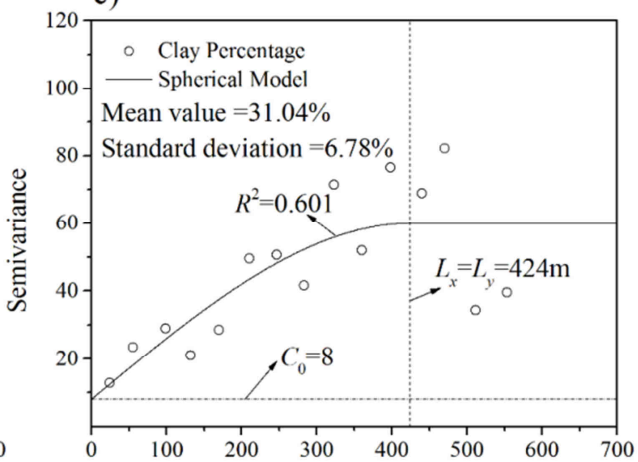

d)

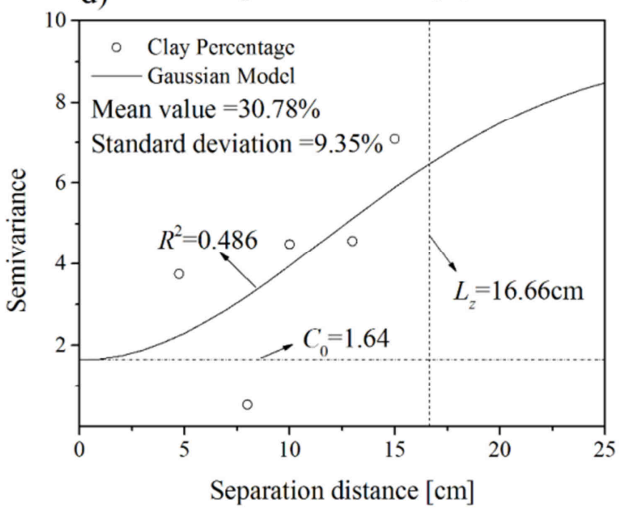

Fig. 3. Relation between semivariance value and separation distance of the spatial distribution of sand and clay percentages ( $\mathrm{a}$ and $\mathrm{b}$ ). The sand percentage distribution in $X-Y$ and $Z$ directions, respectively (c and d). The clay percentage distribution in $X-Y$ and $Z$ directions, respectively. $L_{x}$, $L_{y}$ and $L_{z}$ indicate the correlation scales in $X, Y$, and $Z$ directions, respectively. $C_{0}$ indicates the nugget

Furthermore, after comparing the semivariance value of sand and clay percentages in the direction of $25^{\circ}, 70^{\circ}, 115^{\circ}$, and $160^{\circ}$, we deemed the distribution of sand and clay percentages to be isotropic. More precisely, the mean value, standard deviation, and correlation scale of sand percentage in the $X$ and $Y$ directions were $8.35 \%, 7.22 \%$, and $375 \mathrm{~m}$, respectively (Fig. 3a). In the $Z$ direction, these indexes for sand percentage were $6.21 \%, 4.67 \%$, and $14.83 \mathrm{~cm}$, respectively (Fig. 3b). These geostatistical indexes for clay percentage were also calculated similarly, and the values were $31.04 \%, 6.78 \%$, and $424 \mathrm{~m}$ in the $X$ and $Y$ direction and $30.78 \%, 9.35 \%$, and $16.66 \mathrm{~cm}$ in the $Z$ direction (Fig. 3c-d). 


\section{Surface soil moisture}

On the basis of the wavelength selection principle mentioned in Section "Pre-treatment of hyperspectral data", appropriate wavelengths were selected (Fig. 4) and the relation between reflectance and $S M$ was established by PLSR. Before wavelength selection, the $R M S E$ in the model calibration and validation process were 1.49 and 2.04 , respectively. The $R$ value in the two processes were 0.78 and 0.54 , respectively. After wavelengths selection by VIP scores and $b$-coefficients, the RMSE in the model calibration and validation processes decreased 3.36 and $4.41 \%$, whereas $R$ increased 2.56 and $3.70 \%$, respectively (Table 1).

These low RMSE and high $R$ values indicated the symmetrical distribution of observed and simulated $S M$ and PLSR could be regarded as the optimal method to establish the relations between $S M$ and hyperspectral data by use of the selected wavelengths in our study. This method was applied in the EO-1/Hyperion imagery to estimate surface moisture of the whole study area (Fig. 5).

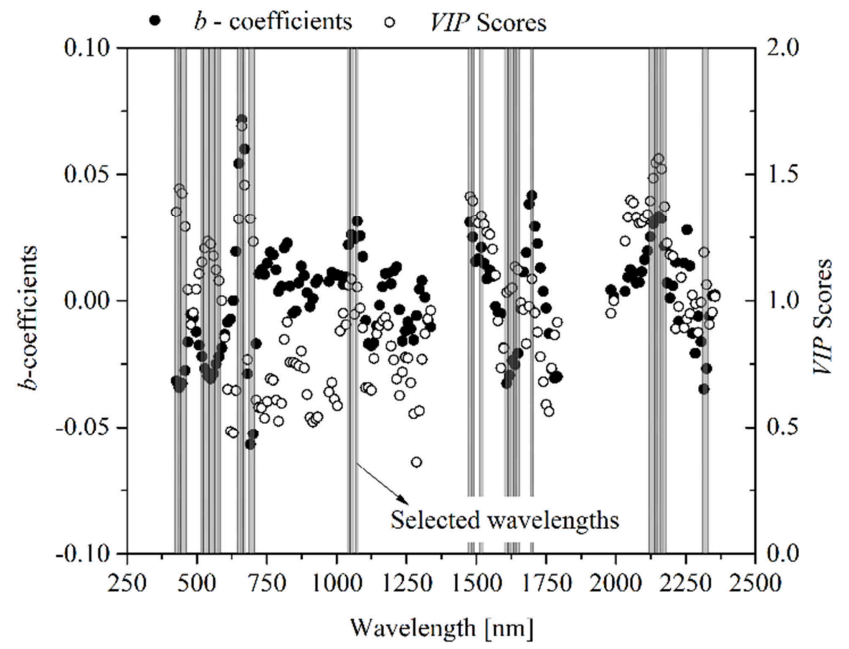

Fig. 4. PLSR coefficients ( $b$-coefficients) and variable importance in projection (VIP) of each wavelength (gray columns indicated the selected wavelengths)

Evaluation of $P L S R$ analysis

\begin{tabular}{|c|c|c|c|}
\hline Processes & $\begin{array}{c}\text { Statistical } \\
\text { indices }\end{array}$ & $\begin{array}{c}\text { Before wavelengths } \\
\text { selection }\end{array}$ & $\begin{array}{c}\text { After wavelengths } \\
\text { selection }\end{array}$ \\
\hline \multirow{2}{*}{ Calibration } & $R$ & 0.78 & 0.80 \\
\cline { 2 - 4 } & $R M S E$ & 1.49 & 1.44 \\
\hline \multirow{2}{*}{ Validation } & $R$ & 0.54 & 0.56 \\
\cline { 2 - 4 } & $R M S E$ & 2.04 & 1.95 \\
\hline
\end{tabular}




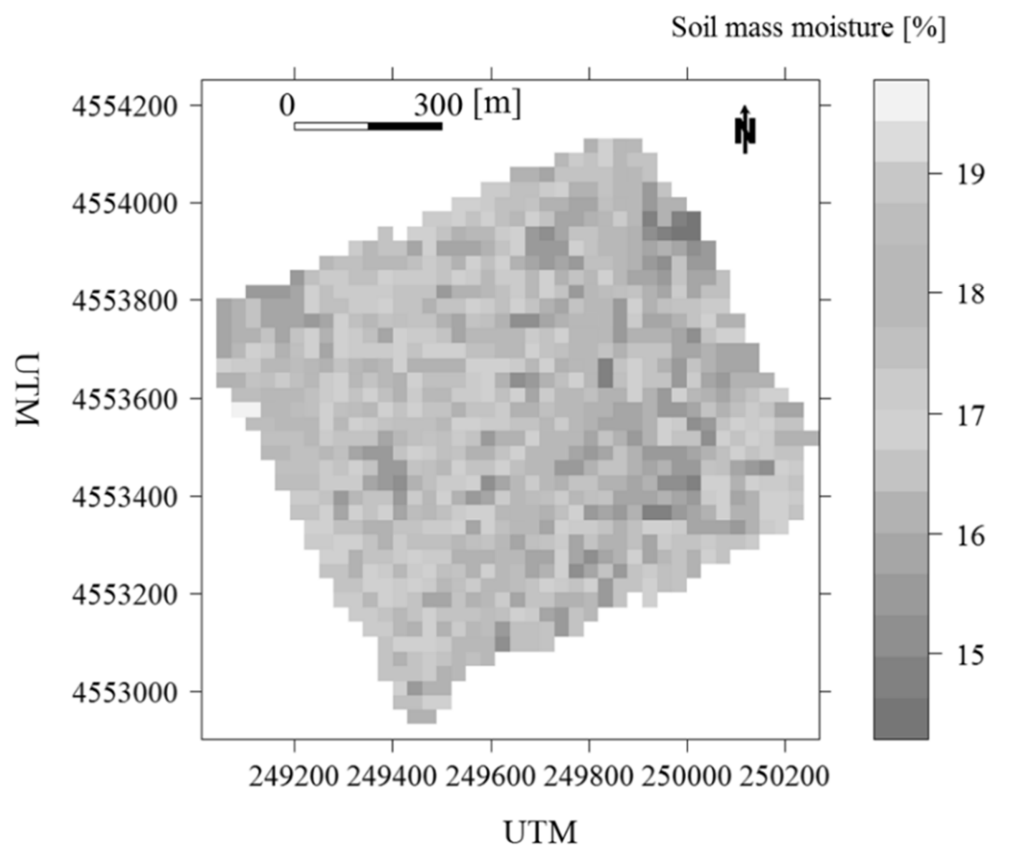

Fig. 5. Surface mass soil moisture [\%] mapped from EO-1/Hyperion imagery. UTM is the abbreviation of Universal Transverse Mercator Grid System

\section{Root zone soil moisture}

In method 1 (M1) to method 3 (M3), the semi-variogram values of observed $S M, S M$ from Hyperion imagery, and observed $R M$ were calculated. The semi-variogram values between $R M$ and observed $S M$ and $S M$ from Hyperion imagery were also calculated before kriging or co-kriging. All of these semi-variogram values could be fitted by use of a spherical model. The Pearson's correlation coefficients $(R)$ were all larger than 0.6 , and all the RMSE values were smaller than 0.5. The nugget, partial sill, and range of each spherical model are shown in Figure 6.

In method 4 (M4), we generated 900 grids in the $X$ and $Y$ directions, and HYDRUS simulation was run 2000 times in each gird. Therefore, for each grid, the coefficients of the linear regression model (e.g., a and b) were determined on the basis of 2000 HYDRUS results, and we could get a total of 900 regression models for our study site in linear regression analysis. Figure 7 is the box plots that indicated the range of coefficients and $R$ values. We found that the 900 coefficients in the linear regression analysis $(a, b$, and $R)$ were similar. More precisely, mean and standard deviation of $a, b$, and $R$ were 0.3566 , 0.2218 , and 0.6900 and $0.0161,0.0031$, and 0.0201 , respectively. Therefore, the linear regression model with the mean value of 900 coefficients (Eq. (4)) was selected to estimate root-zone moisture from surface moisture (M4):

$$
R M=0.3566 \cdot S M+0.1584
$$

In Equation (4), $R M$ and $S M$ indicated the root zone moisture and surface soil moisture in mass unit $\left[\mathrm{g} \cdot \mathrm{g}^{-1}\right]$ respectively. 

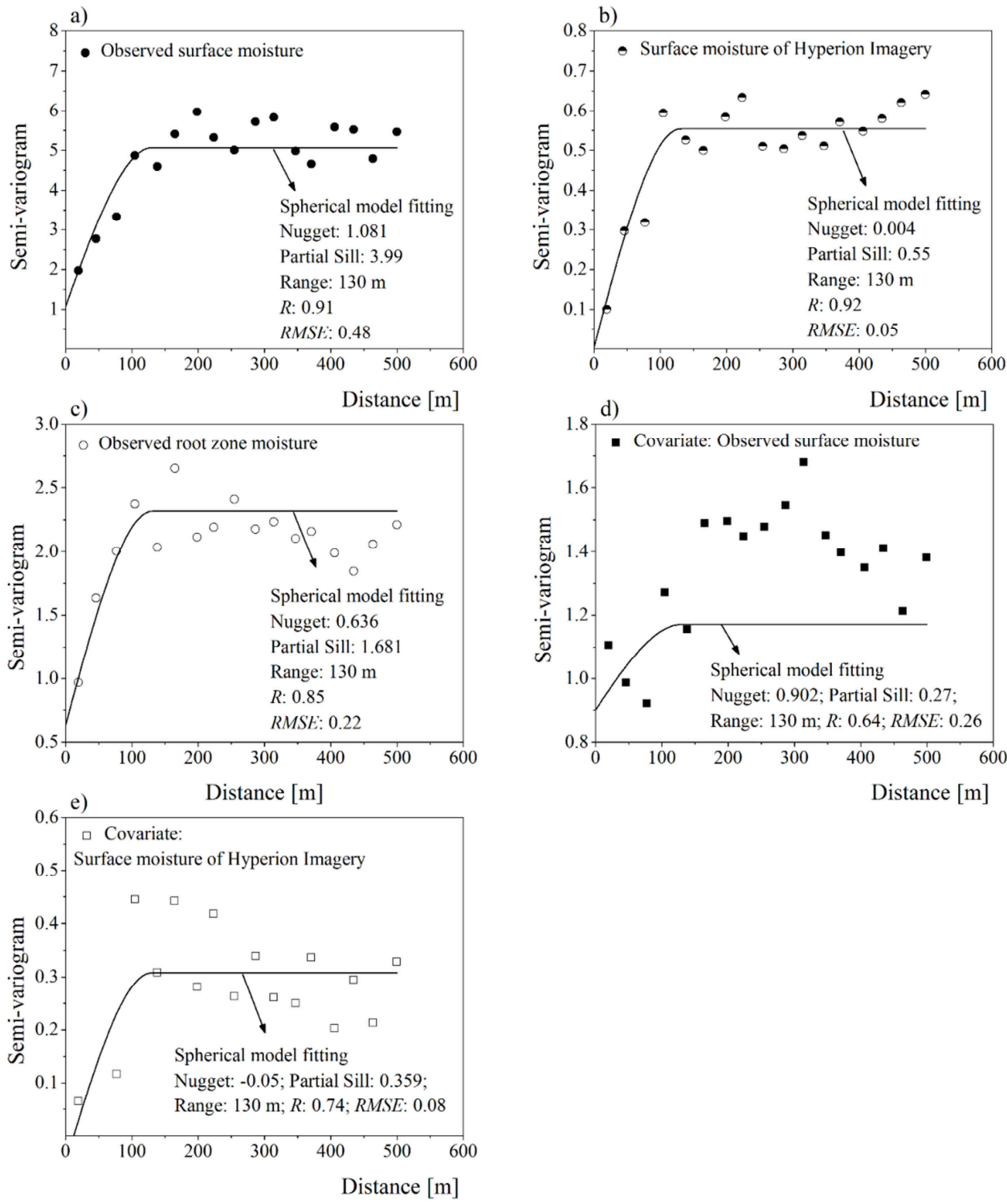

Distance $[\mathrm{m}]$

Fig. 6. Semi-variogram of kriging and co-kriging

Figure 8 indicates the performance of four different methods of estimating root-zone moisture. The RMSE values from M1 to M4 were $1.43,1.32,1.40$, and 0.03 , respectively, and the $R$ values of the four methods were $0.15,0.41,0.27$, and 0.38 , respectively. Therefore, M2 had the highest $R$ value and the $R M S E$ value in M4 was lowest when data in our study were used. 


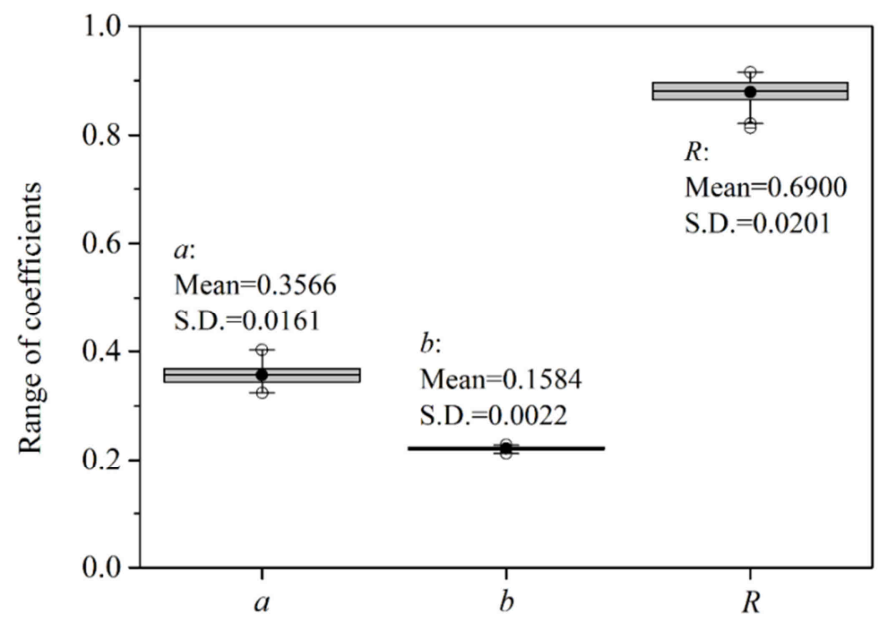

Fig. 7. Box plots of the range of coefficients and $R$ for linear regression analysis with HYDRUS results. The filled points indicated mean value, and open points indicated abnormal value

a)
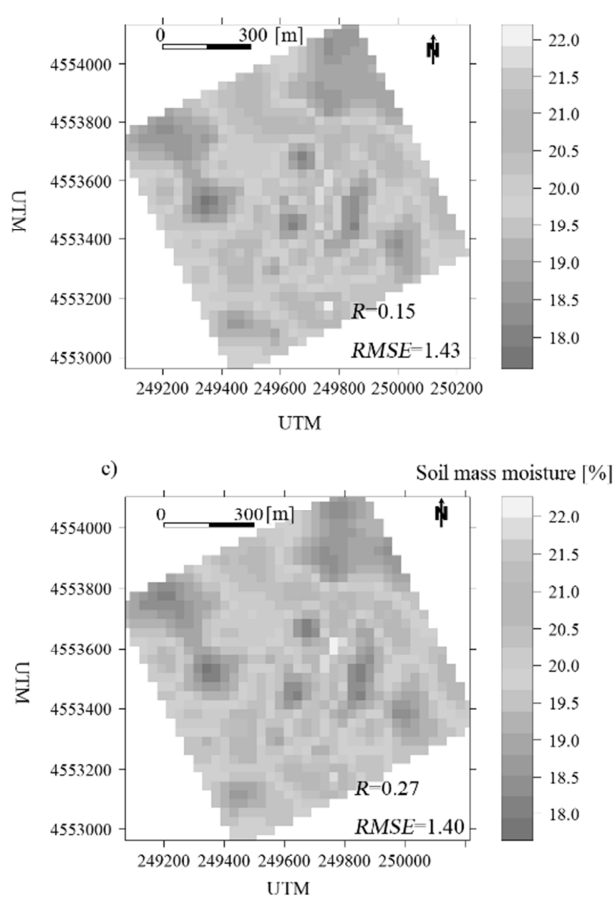

b)
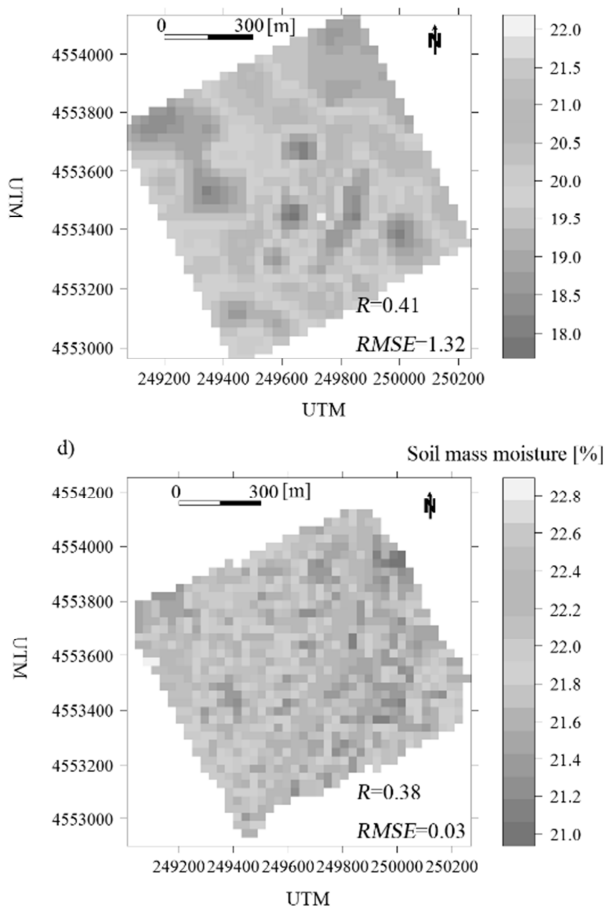

Fig. 8. Root-zone mass moisture and evaluation indices of four different methods: a) kriging, b) co-kriging with observed surface moisture, c) co-kriging with surface moisture obtained from Hyperion imagery, d) linear regression model based on HYDRUS simulations 


\section{Discussion}

\section{Methods for estimating surface soil moisture}

The surface-soil moisture content provides valuable ecosystem services and is critical for both hydrological applications and watershed management [37]. With the development of remote sensing technology, researchers are trying to obtain near-surface moisture content from satellite data. More precisely, they first used satellite images (e.g., MODIS, EO-1/ Hyperion, LANDSAT) to extract valuable information and then establish models to predict near-surface moisture content from this information [38]. However, because of the low resolution of satellite images, estimating the accuracy of model performance when establishing models directly from satellite images might be difficult. For example, the spatial resolution of the MODIS sensor ranges from $250 \mathrm{~m} \times 250 \mathrm{~m}$ to $1 \mathrm{~km} \times 1 \mathrm{~km}$ and although EO-1/Hyperion has higher resolution $(30 \mathrm{~m} \times 30 \mathrm{~m})$, it is still difficult to use soil sampling or other simple methods to obtain the accurate average soil moisture for the specific pixel of a satellite image [14]. Therefore, an increasing number of researchers are using analytical spectral devices (ASDs) to collect coincident soil reflectance and soil moisture measurements and establish models based on these data [39]. After reflectance resampling, the ASD data can match the satellite image exactly [40]. Therefore, our study used the resampled ASD data to establish models and then applied them into the EO-1/Hyperion image. In recent decades, researchers developed many methods to establish soil-moisture prediction models from ASD data.

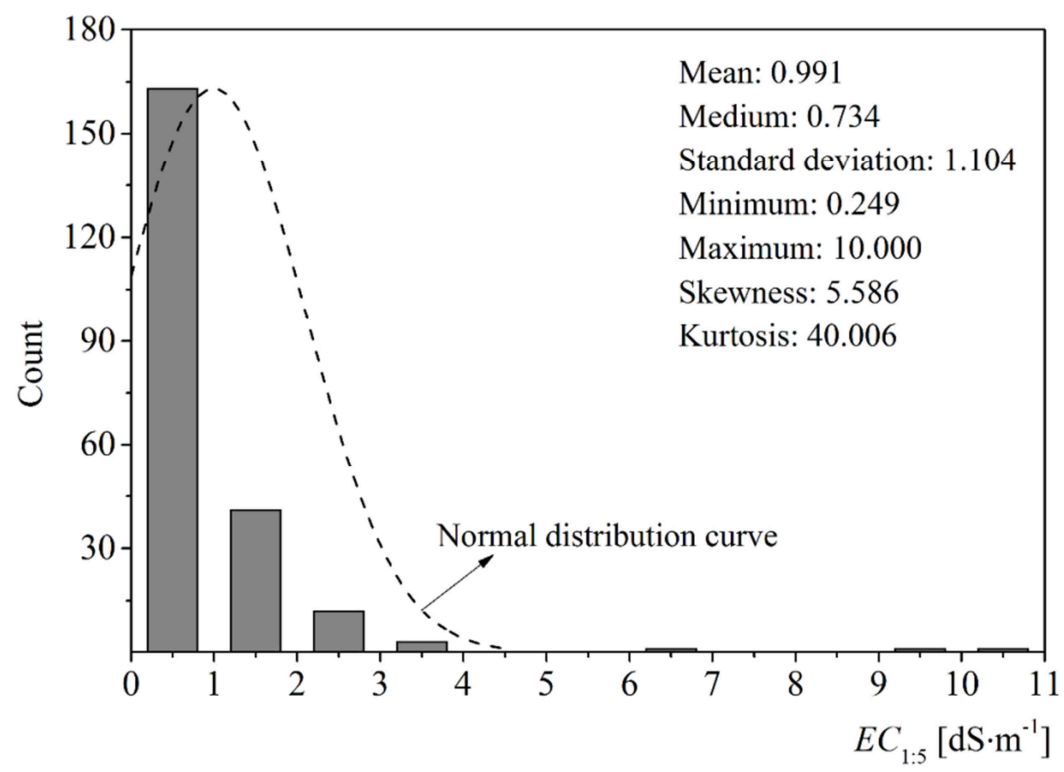

Fig. 9. Histogram of soil-salt content of surface-soil samples taken on April 26 in 2013

For example, Haubrock et al. [41] selected $1800 \mathrm{~nm}$ and $2119 \mathrm{~nm}$ and then used normalized difference $(N D)$ as $S M I$ to predict soil-moisture content; Wang et al. [15] used derivative difference $(d D)$ with the wavelengths of $1300 \mathrm{~nm}$ and $1970 \mathrm{~nm}$ to establish 
a soil-moisture prediction model; and Whiting et al. [42] used a soil reflectance curve to fit the inverted Gaussian function and then extract the geometrical characteristics of the fitted curve to predict water content. However, all these methods were applied in non-saline soils or when the soil-salt content was uniform. In our samples, the salt content varied from soil sample to sample. More precisely, the mean soil-salt content (indicated in $E C_{1: 5}$ ) of 222 surface soil samples ( 5 data points are missing) was $0.99 \mathrm{dS} \cdot \mathrm{m}^{-1}$, but the standard derivation was as large as $1.10 \mathrm{dS} \cdot \mathrm{m}^{-1}$ (Fig. 9). Therefore, we chose the $P L S R$, which can make use of the entire wavelength's information to establish prediction models, and the results ( $R=0.80$ in calibration and 0.56 in validation) proved that PLSR is a powerful tool to predict soil-moisture content based on in situ hyperspectral data in saline soils. The use of $b$-coefficients and VIP to select wavelengths could improve the PLSR accuracy.

\section{Estimating root-zone moisture from surface soil}

Obtaining root-zone moisture information from near-surface has great importance for expanding the application of remote sensing technology and has attracted broad attention, recently [43, 44]. Unlike Manfreda et al. [24] and Kornelsen et al. [45], we did not have extensive time series observations, and we were only concerned with $0-40 \mathrm{~cm}$ (root zone) soil moisture before sowing. Therefore, in M4, we combined Monte Carlo simulation (2000 realizations), geostatistical analysis, and an ANN with the HYDRUS model to obtain the surface and root-zone $(0-40 \mathrm{~cm})$ soil-moisture information. Then, we use regression analysis to establish the root-zone soil-moisture prediction model on the basis of surface moisture $(S M)$. Because $M 4$ was based on the soil physical characteristics of the study area and the calculation was done using HYDRUS, it had a clear physical representation. Therefore, Equation (4) can be used not only in our study area but likely also in regions that have similar climatic and soil conditions. However, although the RMSE is very low compared with the RMSE in other research, the accuracy of estimating root-zone moisture in $M 4$ is not very good. For example, Das et al. [46], using time series measurements and an ensemble Kalman filter $(E n K F)$ technique coupled with a numerical one-dimensional vadose zone flow model (HYDRUS-ET) obtained a highly accurate estimation of $0-60 \mathrm{~cm}$ moisture from surface soil moisture $(R>0.8)$. However, even with time series soil-moisture measurements, the accuracy of root-zone soil-moisture estimation from surface soil varied with different studies [47, 48]. Li et al. [49] indicated that the accuracy of soil-moisture profile retrieval from surface measurements depends strongly on the initial surface soil-moisture conditions. More precisely, they pointed out that wetter surface conditions could provide better root-zone moisture estimations than drier surface conditions. Although we did not have time series observations in our study, no precipitation or irrigation occurred for a long period before our HYDRUS simulation, so we can assume that the link between surface moisture and root-zone moisture was only affected by soil properties. In addition, kriging of observed root-zone moisture $(M 1)$ provided very poor accuracy in our study, whereas co-kriging with observed surface moisture $(M 2)$ had the highest $R(0.41)$ in all four methods (Fig. 8b). It indicated that use of surface moisture as a covariate could improve estimation accuracy. However, when surface moisture retrieved from Hyperion imagery was used as covariate (M3), the $R$ was lower than $M 2$. The possible reasons might be that the observed surface moisture points were large enough and the accuracy of surface moisture retrieved from Hyperion imagery was not as high because the PLSR model was established on the basis of ASD point data, not the Hyperion coarser scale imagery data. 


\section{Conclusion}

Estimation of the soil-moisture profile is necessary for various hydro-meteorological, ecological, and biogeochemical modeling and applications. Remote sensing techniques are increasingly used for monitoring surface soil-moisture conditions over large areas, but extending surface soil moisture to the root zone is still facing some limitations, especially when no time series observations are available, which is very common in practice.

In this study, we retrieved surface moisture from hyperspectral data with $P L S R$, and the calibration and validation process proved that $P L S R$ is a powerful tool for soil-moisture estimation. Then, we compared four different methods, including kriging, co-kriging (using observed data and imagery respectively), and HYDRUS Monte Carlo simulations. Co-kriging with observed surface moisture $(M 2)$ had the highest $R$ and linear regression model, and HYDRUS Monte Carlo simulations (M4) had the lowest RMSE among the four methods. Although the accuracy of $M 4$ was not the highest among these 4 methods, we also recommend this method for root-zone moisture estimation before sowing if no time series observations are available because $M 4$ is based on physical hydrological models and can be easily applied to satellite images.

However, although we considered the distribution of soil hydraulic parameters in the $X, Y$, and $Z$ directions, we only considered water movement in the $Z$ direction because we selected HYDRUS-1D to do calculations. We simplified these processes because the scale of each pixel of EO-1/Hyperion image was large enough $(30 \mathrm{~m} \times 30 \mathrm{~m})$ to regard water movement as one dimensional, and we did not have sufficient observations to validate the parameters of a three-dimensional (3D) water-movement model (e.g., HYDRUS-3D). Therefore, in further research, time series observations should be made, and 3D water-movement models combined with other technology (e.g., data assimilation) can be tried to improve the prediction accuracy.

\section{Acknowledgements}

This work was made possible by support from the State Natural Science Fund (grant No. 51609175, 51790533, and 51379151), China Postdoctoral Science Foundation (grant No. 2017T100579), the Major Program of National Science and Technology Support Plan of China (grant No. 2017YFC0403304 and 2016YFC0501304), the Natural Science Fund of Hubei Province, China (ZRMS2017000430), and the Fundamental Research Funds for the Central Universities (grant No. 2042016kf0043 and 2042016kf1034). Furthermore, the authors appreciate the feedback received by Dr. Willem van Leeuwen at the Arizona Remote Sensing Center, The University of Arizona, on an earlier version of this manuscript.

\section{References}

[1] Callaghan MV, Head FA, Cey EE, Bentley LR. Salt leaching in fine-grained, macroporous soil: Negative effects of excessive matrix saturation. Agricult Water Manage. 2017;181:73-84. DOI: 10.1016/j.agwat.2016.11.025.

[2] He K, Yang Y, Yang Y, Chen S, Hu Q, Liu X, et al. Hydrus simulation of sustainable brackish water irrigation in a winter wheat-summer maize rotation system in the north china plain. Water. 2017;9(7):536. DOI: 10.3390/w9070536.

[3] Trujillo-González J, Mahecha-Pulido J, Torres-Mora M, Brevik E, Keesstra S, Jiménez-Ballesta R. Impact of potentially contaminated river water on agricultural irrigated soils in an equatorial climate. Agriculture. 2017;7(7):52. DOI: 10.3390/agriculture7070052. 
[4] Li Y, Šimůnek J, Wang S, Yuan J, Zhang W. Modeling of soil water regime and water balance in a transplanted rice field experiment with reduced irrigation. Water. 2017;9(4):248. DOI: 10.3390/w9040248.

[5] García-Garizábal I, Causapé J, Merchán D. Evaluation of alternatives for flood irrigation and water usage in spain under mediterranean climate. CATENA. 2017;155:127-134. DOI: 10.1016/j.catena.2017.02.019.

[6] Jalali V, Asadi Kapourchal S, Homaee M. Evaluating performance of macroscopic water uptake models at productive growth stages of durum wheat under saline conditions. Agricult Water Manage. 2017;180:13-21. DOI: 10.1016/j.agwat.2016.10.015

[7] Hassan-Esfahani L, Torres-Rua A, Jensen A, Mckee M. Spatial root zone soil water content estimation in agricultural lands using bayesian-based artificial neural networks and high-resolution visual, nir, and thermal imagery. Irrigation Drainage. 2017;66(2):273-288. DOI: 10.1002/ird.2098.

[8] Veihmeyer FJ, Hendrickson AH. The moisture equivalent as a measure of the field capacity of soils. Soil Sci. 1931;32(3):181-194. DOI: 10.1097/00010694-193109000-00003.

[9] Shepherd KD, Walsh MG. Development of reflectance spectral libraries for characterization of soil properties. Soil Sci Soc Am J. 2002;66(3):988-998. DOI: DOI: 10.2136/sssaj2002.9880.

[10] Nanni MR, Demattê JAM. Spectral reflectance methodology in comparison to traditional soil analysis. Soil Sci Soc Am J. 2006;70:393-407. DOI: 10.2136/sssaj2003.0285.

[11] Tucker CJ, Pinzon JE, Brown ME, Slayback DA, Pak EW, Mahoney R, et al. An extended AVHRR 8-km NDVI dataset compatible with modis and spot vegetation NDVI data. Int $J$ Remote Sens. 2005;26(20):4485-4498. DOI: 10.1080/01431160500168686.

[12] Liu G, Guo H, Yan S, Song R, Ruan Z, Lv M. Revealing the surge behaviour of the yangtze river headwater glacier during 1989-2015 with tandem-x and landsat images. J Glaciology. 2017;63(238):382-386. DOI: 10.1017/jog.2017.4.

[13] Shahtahmassebi AR, Lin Y, Lin L, Atkinson PM, Moore N, Wang K, et al. Reconstructing historical land cover type and complexity by synergistic use of landsat multispectral scanner and corona. Remote Sensing. 2017;9(7):682. DOI: 10.3390/rs9070682.

[14] Yu H, Kong B, Wang G, Du R, Qie G. Prediction of soil properties using a hyperspectral remote sensing method. Archives Agronomy Soil Sci. 2017:1-14. DOI: 10.1080/03650340.2017.1359416.

[15] Rocha Neto O, Teixeira A, Leão R, Moreira L, Galvão L. Hyperspectral remote sensing for detecting soil salinization using prospectir-vs aerial imagery and sensor simulation. Remote Sensing. 2017;9(1):42. DOI: $10.3390 /$ rs9010042.

[16] Ben-Dor E, Chabrillat S, Demattê JAM, Taylor GR, Hill J, Whiting ML, et al. Using imaging spectroscopy to study soil properties. Remote Sens Environ. 2009;113:S38-S55. DOI: 10.1016/j.rse.2008.09.019.

[17] Calzolari C, Ungaro F. Predicting shallow water table depth at regional scale from rainfall and soil data. J Hydrol. 2012;414:374-387. DOI: 10.1016/j.jhydrol.2011.11.008.

[18] Vauclin M, Vieira S, Vachaud G, Nielsen D. The use of cokriging with limited field soil observations. Soil Sci Soc Am J. 1983;47(2):175-184. DOI: 10.2136/sssaj1983.03615995004700020001x.

[19] Sun RH, Liu QL, Chen LD. Study on precipitation based on the geostatistical analyst method. J China Hydrol. 2010;30(1):14-18. DOI: 10.3969/j.issn.1000-0852.2010.01.003.

[20] Yates SR, Warrick AW. Estimating soil water content using cokriging. Soil Sci Soc Am J. 1987;51(1):23-30. DOI: 10.2136/sssaj1987.03615995005100010005x.

[21] Ghadermazi J, Sayyad G, Mohammadi J, Moezzi A, Ahmadi F, Schulin R. Spatial prediction of nitrate concentration in drinking water using ph as auxiliary co-kriging variable. Procedia Environ Sci. 2011;3(0):130-135. DOI: 10.1016/j.proenv.2011.02.023.

[22] Regalado CM, Ritter A, Rodríguez-González RM. Performance of the commercial wet capacitance sensor as compared with time domain reflectometry in volcanic soils. Vadose Zone J. 2007;6(2):244-254. DOI: 10.2136/vzj2006.0138.

[23] Blonquist Jr J, Jones SB, Robinson D. A time domain transmission sensor with tdr performance characteristics. J Hydrol. 2005;314(1):235-245. DOI: 10.1016/j.jhydrol.2005.04.005.

[24] Manfreda S, Brocca L, Moramarco T, Melone F, Sheffield J. A physically based approach for the estimation of root-zone soil moisture from surface measurements. Hydrol Earth Syst Sci. 2014;18(3):1199-1212. DOI: 10.5194/hess-18-1199-2014.

[25] Noborio K. Measurement of soil water content and electrical conductivity by time domain reflectometry: A review. Comput Electron Agr. 2001;31(3):213-237. DOI: 10.1016/S0168-1699(00)00184-8.

[26] Kilmer VJ, Alexander LT. Methods of making mechanical analyses of soils. Soil Sci. 1949;68(1):15-24. DOI: 10.1097/00010694-194907000-00003.

[27] Geladi P, Kowalski BR. Partial least-squares regression: A tutorial. Analytica Chim Acta. 1986;185:1-17. DOI: $10.1016 / 0003-2670(86) 80028-9$. 
[28] Wold S, Ruhe A, Wold H, Dunn WJ. The collinearity problem in linear regression. The partial least squares (pls) approach to generalized inverses. SIAM J Sci Stat Computing. 1984;5(3):735-743. DOI: $10.1137 / 0905052$.

[29] Helland IS. On the structure of partial least squares regression. Communic Statistics-Simul Comput. 1988;17(2):581-607. DOI: 10.1080/03610918808812681.

[30] Abdi H. Partial least squares regression and projection on latent structure regression (pls regression). Wiley Interdisciplin Reviews: Computat Statistics. 2010;2(1):97-106. DOI: 10.1002/wics.51.

[31] Gomez C, Viscarra Rossel RA, Mcbratney AB. Soil organic carbon prediction by hyperspectral remote sensing and field vis-nir spectroscopy: An Australian case study. Geoderma. 2008;146(3):403-411. DOI: 10.1016/j.geoderma.2008.06.011.

[32] Chen H, Pan T, Chen J, Lu Q. Waveband selection for NIR spectroscopy analysis of soil organic matter based on SG smoothing and MWPLS methods. Chemometrics Intell Labor Systems. 2011;107(1):139-146. DOI: 10.1016/j.chemolab.2011.02.008

[33] Tsai F, Philpot W. Derivative analysis of hyperspectral data. Remote Sens Environ. 1998;66(1):41-51. DOI: 10.1016/S0034-4257(98)00032-7.

[34] Van Genuchten MT. A closed-form equation for predicting the hydraulic conductivity of unsaturated soils. Soil Sci Soc Am J. 1980;44(5):892-898. DOI: 10.2136/sssaj1980.03615995004400050002x.

[35] Schaap MG, Leij FJ, Van Genuchten MT. Rosetta: A computer program for estimating soil hydraulic parameters with hierarchical pedotransfer functions. J Hydrol. 2001;251(3-4):163-176. DOI: 10.1016/s0022-1694(01)00466-8.

[36] Hu SZ, Qiao DM, Shi HB. Analysis on root ecological and physiological characteristics of sunflower. J Arid Land Resour Environ. 2006;20(6):192-197. DOI: 10.3969/j.issn.1003-7578.2006.06.037.

[37] Zeng W, Xu C, Wu J, Huang J, Zhao Q, Wu M. Impacts of salinity and nitrogen on the photosynthetic rate and growth of sunflowers (Helianthus annuus 1.). Pedosphere. 2014;24(5):635-644. DOI: 10.1016/S1002-0160(14)60049-7.

[38] Holzman ME, Rivas R, Piccolo MC. Estimating soil moisture and the relationship with crop yield using surface temperature and vegetation index. Int J Appl Earth Observ Geoinformation. 2014;28:181-192. DOI: 10.1016/j.jag.2013.12.006.

[39] Lobell DB, Asner GP. Moisture effects on soil reflectance. Soil Sci Soc Am J. 2002;66(3):722-727. DOI: $10.2136 /$ sssaj2002.7220.

[40] Morel J, Bégué A, Todoroff P, Martiné J-F, Lebourgeois V, Petit M. Coupling a sugarcane crop model with the remotely sensed time series of fipar to optimise the yield estimation. Eur J Agron. 2014;61:60-68. DOI: 10.1016/j.eja.2014.08.004.

[41] Haubrock SN, Chabrillat S, Lemmnitz C, Kaufmann H. Surface soil moisture quantification models from reflectance data under field conditions. Int J Remote Sens. 2008;29(1):3-29. DOI: 10.1080/01431160701294695.

[42] Whiting ML, Li L, Ustin SL. Predicting water content using Gaussian model on soil spectra. Remote Sens Environ. 2004;89(4):535-552. DOI: 10.1016/j.rse.2003.11.009.

[43] Diepen CV, Wolf J, Keulen HV, Rappoldt C. Wofost: A simulation model of crop production. Soil Use Manage. 1989;5(1):16-24. DOI: 10.1111/j.1475-2743.1989.tb00755.x.

[44] Boogaard H, Wolf J, Supit I, Niemeyer S, Van Ittersum M. A regional implementation of wofost for calculating yield gaps of autumn-sown wheat across the European Union. Field Crop Res. 2013;143:130-142. DOI: $10.1016 /$ j.fcr.2012.11.005

[45] Kornelsen K C, Coulibaly P. Root-zone soil moisture estimation using data-driven methods. Water Resour Res. 2014;50(4):2946-2962. DOI: 10.1002/2013WR014127.

[46] Das NN, Mohanty BP. Root zone soil moisture assessment using remote sensing and vadose zone modeling. Vadose Zone J. 2006;5(1):296-307. DOI: 10.2136/vzj2005.0033.

[47] Zeng W, Xu C, Huang J, Wu J, Tuller M. Predicting near-surface moisture content of saline soils from near-infrared reflectance spectra with a modified Gaussian model. Soil Sci Soc America J. 2016;80(6):1496-1506. DOI: 10.2136/sssaj2016.06.0188.

[48] Wigneron JP, Olioso A, Calvet JC, Bertuzzi P. Estimating root zone soil moisture from surface soil moisture data and soil-vegetation-atmosphere transfer modeling. Water Resour Res. 1999;35(12):3735-3745. DOI: 10.1029/1999WR900258.

[49] Li J, Islam S. Estimation of root zone soil moisture and surface fluxes partitioning using near surface soil moisture measurements. J Hydrol. 2002;259(1):1-14. DOI: 10.1016/S0022-1694(01)00589-3. 